\title{
NEONATAL ARTHRITIS DUE TO PROTEUS VULGARIS
}

\author{
BY \\ ANDREW BOGDANOVITCH, M.B., D.C.H. \\ (From the Hospital for Sick Children, Great Ormond Street, London)
}

The main feature of this case is a bilateral purulent sterno-clavicular arthritis, which was secondary to umbilical infection. The case is described in view of the rarity of Proteus vulgaris infections of this type. The umbilicus is a frequent site of entrance of pyogenic infection in the neonatal period, and the full development of such an infection may manifest itself in many ways, including jaundice, meningitis, septicaemia, etc. Proteus vulgaris is normally found in decomposing organic matter of animal origin, such as sewage. It is also found in human faeces when normal intestinal mechanism is deranged, and Neter (1945) even found that $\mathbf{4 0}$ per cent. of normal infants under the age of one year, with no history of diarrhoea or similar disturbance, had this organism cultured from their rectal swabs.

It is of interest to note that Topley and Wilson (1946) give Proteus vulgaris as the fourth commonest organism to wound infection. Staphylococcus aureus, Streptococcus pyogenes, and Bacillus coli preceded Proteus vulgaris in that order. The umbilicus of a newly-born infant is liable to similar infection. Proteus vulgaris, when pathogenic, is responsible for inflammatory lesions such as cystitis. It also may give rise to abscess formation.

\section{Case History}

The patient, the second child of a healthy mother, was a girl born on June 29,1946 , one week prematurely, with a birth weight of $7 \mathrm{lb}$. $9 \mathrm{oz}$. The delivery was normal and spontaneous, requiring no instruments, but the infant was noticed to be cyanosed, and had to be given oxygen and coramine for the first two days of life. There was gradual improvement until the fourth day, when she became jaundiced and developed a temperature of $102^{\circ} \mathrm{F}$. Examination of the urine revealed a Bacillus coli infection, which was treated with sulphathiazole and alkalis. A total of $3.25 \mathrm{gr}$. of sulphathiazole was given over four days.

On July 10 the infant was noticed to have swellings over both sterno-clavicular joints, and the urine still remaining infected; the sulphathiazole was replaced by sulphadiazine. On the following day the swellings were aspirated, and pus was withdrawn from the right sterno-clavicular joint, the fluid from the left joint being quite clear. Penicillin was commenced orally, 3,000 units being given every three hours. A catheter specimen of urine still revealed the presence of Bacillus coli in pure culture.

At this point the child was admitted to the Hospital for Sick Children, Great Ormond Street, London. The general condition was good. The infant was well hydrated, the mouth clean, and the eardrums were normal, but both sterno-clavicular joints were still greatly distended, and there was some discharge from the umbilicus, with a temperature of $101^{\circ} \mathrm{F}$. The liver and spleen were not palpable. There was no oedema.

InVESTIGATIONS. Fluid from the right sternoclavicular joint was purulent, from the left clear, and yellowish in colour. Each gave a pure growth of Proteus vulgaris. Blood culture showed no growth. The blood count was as follows: $\mathrm{Hb}$ 110 per cent.; red blood cells $5 \cdot 1$ million per c.mm. of blood; white blood cells 19,200 per c.mm., with polymorphs 68 per cent. and lymphocytes 32 per cent.

An umbilical swab yielded a pure culture of Proteus vulgaris, and a nasal swab was Staphylococcus aureus coagulase-positive. A post-nasal swab revealed Bacillus subtilis and Staphyloccus albus. No pathogens were isolated from a rectal swab.

A radiograph of the chest and sterno-clavicular joints showed no abnormality.

Progress and Treatment. Penicillin was continued, but, instead of orally, 1,500 units were given three-hourly by intramuscular injections. In addition, soon after admission (July 13, 1946), 1,000 units of penicillin were instilled into each sternoclavicular joint after aspiration. On the next day (July 14) the umbilicus was already becoming cleaner, but it was decided to reinforce the penicillin with sulphadiazine in $0.25 \mathrm{~g}$. doses six-hourly. The temperature had now become normal, and the swelling of the joints had diminished. The child was taking the breast well and was gaining weight.

On July 15 discharge from the umbilicus had ceased, but pus was again aspirated from the left sterno-clavicular joint and 1,000 units of penicillin were again instilled. Two days later the left joint was again aspirated and 1,000 units of penicillin instilled.

The Proteus vulgaris isolated in culture was found to be sensitive only to a concentration of $\mathbf{4 0}$ units of penicillin per $100 \mathrm{ml}$., a concentration which could only be achieved by local administration. 
Systemic penicillin was accordingly discontinued, but the next day the temperature rose to $99^{\circ} \mathrm{F}$., and it was therefore recommenced. The joint swellings had become less, the left more so than the right, and on July 23 penicillin was discontinued. A total of 106,000 units of penicillin had been given intramuscularly over fourteen days, with 1,000 units into the right joint, and 3,000 units in all into the left joint, thus making a grand total of 110,000 units.

The administration of sulphadiazine was stopped two days later (July 25), the total dosage being $11 \cdot 75 \mathrm{~g}$.

On discharge (July 28) the umbilicus was quite clean, and only slight swelling of both sternoclavicular joints remained. The leucocyte count had fallen to 15,100 per c.mm. per cent. blood, with 41 per cent. polymorphs. Whilst in hospital the child, who had never appeared very ill, had made a steady gain in weight of $1 \mathrm{lb}$. $5 \mathrm{oz}$. during the 18 days.

When the child was seen a month after discharge, the left sterno-clavicular joint showed some deformity, and a radiograph revealed rarefaction of the inner end of the left clavicle with some derangement of the left sterno-clavicular joint. Apart from this the general condition of the child was excellent.

The child was next seen when it was nine months old. Her weight was $19 \mathrm{lb} .10 \mathrm{oz}$., and she looked extremely well. There was no apparent deformity of either sterno-clavicular joint, and movement at both joints seemed satisfactory. A radiograph, however, revealed that both joints were probably dislocated, and there was some consolidated widening at the inner ends of both clavicles. There was no evidence of bony destruction.

\section{Conchusion}

From this case it appears that Bacillus proteus infections in infancy, especially if localized, may be treated with full doses of sulphadiazine and penicillin with some hope of success. The non-irritability of the latter makes it suitable for local administration in high dosage. This in itself is probably as important as the rest of the treatment.

\section{Summary}

A case of Proteus vulgaris infection of both sternoclavicular joints has been described.

The infection appeared secondary to that of the umbilicus.

Such cases are rare and usually fatal. The successful use of sulphadiazine with local and systemic penicillin is described.

I am indebted to Dr. Bernard Schlesinger for his help and permission to publish this case, to Dr. I. A. B. Cathie for advice on the bacteriological aspect, and to Dr. G. M. Donaldson for assistance on the ward.

\section{REFERENCES}

Neter, E., (1945). J. Pediat., 26. 390.

Topley, and Wilson, (1946). Principles of Bacteriology and Immunity. 3rd Edit. pp. 642-651; 1501; and 1586.

\section{REVIEWS}

The Child's Lumg : Developmental Amatomy, Physiology and Pathology. By STEFAN ENGel, M.D., Formerly Associate Professor of Pediatrics, Medical Academy in Düsseldorf; Special Research Fellow, The Hospital for Sick Children, Great Ormond Street, London. 1947. London: Edward Arnold and Co. Pp. 330. (Price 40s.)

In his preface, the author stresses his approach to the clinical aspects of pulmonary disease in childhood through morphological study of the respiratory system, and the need for three-dimensional methods in appreciating bronchial and lung structure. Much work has already been done along these lines, and unfortunately Part $I$ of this book (which deals with the bronchial tree and bronchial glands) loses much of its value since most of the specimens from which the author obtained his data were Wood's metal casts, which lead to distortion of the bronchi. The best section in this part is that dealing with the bronchiolar wall. Chapter 18 ('The Elements of the LungTissue ') gives a fair representation of the views held today, with perhaps the exception of the author's criticisms of Baltisberger on p. 229 . It is curious that, whilst many people have failed to confirm Baltisberger's findings, there are some who have succeeded in demonstrating in normal healthy animal lungs, chiefly dog, muscle network around the alveolar duct. It is possible that there is a species difference, and also a particular technique necessary for their demonstration. Chapter 19 ("The Blood Supply of the Lung-Tissue ') consists of one page only, and does not even mention the bronchial vascular system, which supplies all the lung tissues with the exception of the portion of the respiratory tree distal to the respiratory bronchioles.

Whilst there is clearly a place for an authoritative work on the field with which the author has dealt, it must be admitted that this particular volume is not entirely adequate. The present high cost of book production perhaps tends to sharpen criticism of the matter published, but where certain aspects of the_subject (for example the pathology included in Part I) have been equally well dealt with by other 